\title{
11. Pathologies of Collective Recognition ${ }^{1}$
}

\section{by Onni Hirvonen}

\section{Introduction}

As a critical social theory, the theory of recognition is focused on the pathologies of the social world (Honneth, 2007; Honneth, 2009). The common intuitions behind various recognition theories are that recognition - as positive status attribution - is important for a good life, and that recognition is also a political concept that holds the key to determining what a good society is. Pathology, in turn, is a term that has been recently used to describe either the failures of realizing recognition relationships successfully or the inherent dangers that unstable or ambivalent recognition relationships pose (Canivez, 2011, 882-883). The aim of any critical social theory is to explain and understand social pathologies and, where possible, provide remedies and suggestions on how to run our social life in a successful manner. Instead of analyzing the practical pathologies of recognition, this article has a more meta-theoretical and descriptive aim: that is, to explore the possibilities of pathologies of collective recognition.

Pathologies of recognition are often understood as collective in their nature. Examples include systemic and institutional problems in providing opportunities for flourishing lives, cultural biases and racism, problems of international politics and even war (see e.g. Lindemann, 2010; Lindemann \& Ringmar, 2012; Martineau, Meer \& Thompson, 2012). It is true that in some primitive sense all pathologies of recognition are collective pathologies, given that recognition is defined in terms of interpersonal social interaction. However, it seems that there is also a different sense of 'collective' at work in recognition theoretical discussions: namely, collectives as groups of people who are conceived of as subjects and objects of recognition in themselves.

Thus, to map out the possibilities of conceptualizing collective pathologies from a recognition-theoretical perspective, we need to first analyze the role of collectives in recognition. This is done in section 2 by, firstly, offering a broad definition of recognition as a multi-dimensional phenomenon with varying success conditions and, secondly, distinguishing between vertical and horizontal forms of recognition. With these distinctions, it is argued that collectives have a twofold role in recognition - as normative frameworks and as agents.

After what is meant by collective recognition has been established, we 
turn to defining pathologies of recognition (section 3). The aim is to provide a broad understanding of pathologies of recognition as systematic deviations from the key norms of recognition. With this definition in place, it becomes possible to analyze the role of collectives in pathologies of recognition (section 4). It is suggested that, firstly, collective pathologies can be either systemic or agential and that, secondly, if we accept the existence of collective agents in society, that opens possibilities for specific collective pathologies. Though some of the current literature on collective recognition and its pathologies suggests that groups do indeed have some sort of agential role, the question of whether the Hegelian concept of mutual recognition lends itself at all to the kind of 'collectivizing' move that genuine collective pathologies of recognition would suggest is still very much open. The concluding section (5) offers a short analysis of the ontological commitments that need to be made if one wants to understand pathologies of recognition as including collective agents.

\section{Recognition: Social and Collective}

If one is to map out and analyze pathologies of collective recognition, as we have set out here to do, it has to be made clear what we mean by collective recognition. Recognition amongst and between states, corporations, parties, and various other social groups is often discussed, but at the same time it is not clear that these relations and their potential pathologies are best understood within the same conceptual framework as recognition between individual agents. However, before analyzing the possibilities of collective recognition, it is useful to say a few words about recognition as such.

Most readings of recognition (e.g. Honneth, 1995; Taylor, 1994) share a common Hegelian intuition that has been spelled out by Ikäheimo (2002a, 450) as saying that recognition is taking another as a person so that the other understands and accepts this attitude. Recognition is understood as having a special role as a phenomenon that is responsive to personhood but at the same time also creates or constitutes it (Ikäheimo, 2007, 227-228). In other words, only persons can be recognized in the Hegelian sense of the term but at the same time we are persons only through being recognized as such. As Taylor $(1994,26)$ puts it, recognition of this kind is a 'vital human need.' In addition, it is often thought that our needs for recognition also have an effect on the desirable structuration of a society. As Thompson (2006, 9) summarizes, political theories of recognition hold that it is exactly recognition that holds the key for determining what is just in a society and what a good society is. In short, recognition, in a broad sense of the word, is understood as positive status attribution that happens between persons and also constitutes those persons. This is combined with the insight that 
personhood is a politically significant concept and thus that recognition also has a central role in politics. This is the so-called broad Hegelian sense of recognition that - despite the various differences in details - can be seen behind most contemporary theories of recognition. ${ }^{2}$

This broad Hegelian idea of recognition is often understood to be multi-dimensional and also historical, in the sense that practical recognition relationships take different historical forms that have their own norms and are responsive to different psychological capabilities. For example, Honneth's (1995, 129) distinctions between love as emotional support, respect for moral responsibility, and esteem for traits and abilities gives us three forms of recognition that are responsive to different aspects of historically defined personhood. These forms of recognition are, in turn, solidified in the institutional world and form institutionalized recognition frameworks, in the light of which individuals may grant normative statuses to each other (Honneth, 2011, 403). As Joel Anderson aptly summarizes:

(1) Humans have an historically conditioned but anthropologically grounded need for relations of mutual recognition and the associated forms of social freedom. (2) These recognition relations are in turn dependent on something like a socio-cultural ecosystem. (Anderson, 2013, 18.)

There are two different senses in which the word 'collective' ${ }^{3}$ can be used in the context of recognition as described above. The first is the trivial one: that recognition is collective insofar as it consists of interpersonal social actions that happen within a shared normative framework of recognition institutions. Recognition in this sense is not private or atomistic but rather dependent on a broader social setting.

Linked to this idea of normative frameworks of recognition is the common idea that, in addition to the horizontal recognition that happens between agents, we also need to vertically recognize the recognition institutions within which the horizontal recognition functions (e.g. Canivez, 2011; Ikäheimo, 2014; Siep, 1974). Like any other normative system, the normative frameworks of recognition require collective acceptance to exist. However, it is unclear if the vertical recognition of institutions is recognition in the Hegelian person-constituting sense of the word or mere acceptance of a system of recognition-norms.

In addition to the overall social or collective nature of recognition, there is also a second sense in which collectives figure in recognition discussions. Namely, as subjects and objects of recognition. This differs from the recognition of a recognition framework in the sense that collectives now have an agential role within a normative framework. For example, we may 
argue for recognition of cultures (Taylor, 1994), see recognition relationships between states as the part and parcel of international politics (Lindemann, 2010; Lindemann \& Ringmar, 2012), or understand new social movements as the driving force in struggles for recognition (Honneth, 1995). In these cases it is clear that groups and collectives feature as active participants in recognition, instead of only taking the role of providing background conditions for recognition.

This is a point that is not captured by the distinction between the horizontal 'I-You' recognition and the vertical 'I-We' recognition. While the 'I-You' is supposed to cover the reciprocal inter-individual recognition and 'I-We' the asymmetrical individual-community recognition (Canivez, 2011, 855), those relationships where collectives function as agents in reciprocal relationships are passed over. Though it is questionable whether collectives can function as agents at all, in many cases recognition theorists at least make an implicit reference to collective agents. States, minority cultures and social movements are common examples of supra-individual agents that have an active role in the struggles for recognition.

It is possible to distinguish different agential roles or 'action positions' that collectives may take in recognition relationships. Firstly, there is recognition between the group itself and the members of the group. Examples of this kind of recognition include various forms of institutional esteem for the members (e.g. corporate pay raises for workers) or the individuals' acceptance of the institution they belong to (e.g. acceptance of board decisions). It may be possible to understand Canivez's $(2011,862)$ idea of 'I-We' recognition where the 'We' is a subject as an exemplar of this kind of in-group recognition. However, Canivez seems to combine both the acceptance of a normative framework and recognition of a collective as a subject in the same idea of 'I-We' recognition. Furthermore, it should be noted that the 'in-group agent' that is in a recognition relationship with the group may well be a group in itself. Relationships between political parties - subgroups of a state - and a state can be considered as an example of this.

The second way in which collectives may act in recognition is recognition between a group and an individual who is not a member of the group. This 'I-Them' or 'We-(singular)You' recognition differs from the 'IWe' recognition as it may be assumed that the 'I-We' recognition includes an element of recognizing oneself as a member of a group and thus the recognitive attitude is at the same time directed towards oneself. In the case that one is not a member of the group, the situation seems largely analogous to recognition between two individuals. It is also clear that the 'outgroup agent' may be a group. The examples of recognition between separate groups include recognition amongst states or recognition between corporate agents. 
If we accept the broad Hegelian sense of recognition, in which recognitive attitudes are attitudes towards persons, the agential roles of collectives in recognition rely on the assumption that groups can be taken as personifiable subjects in themselves. As List and Pettit (2011, 174-176) ${ }^{4}$ show, we have a long history of practical personifying attitudes towards collective agents and arguably these attitudes towards groups are also reflected in the Hegelian tradition (see e.g. Tuomela, 2013, 3). Though the questions of collective agency and collective personhood will be left unresolved here, the practical attitudes can be supported by a wealth of philosophical arguments for collective personhood (e.g. French, 1979; Rovane, 1998; List and Pettit, 2011).

Even if one accepts the existence of group persons in some sense, this does not yet mean that recognizing groups as persons is the same kind of 'taking-as-a-person' as with individuals. It is often thought that personhood consists of certain capabilities and statuses (Laitinen, 2007, 248-249). In a recognition-theoretical setting this means that different forms of recognition are based on different actual or potential capabilities that the recognized agent has. Thus, if group agency is in some relevant sense different from individual agency, this also has implications for the possible forms of recognition that collective recognition may take. Though we do not have the time or space to analyze the range of differences here, the possibility of those differences must be kept in mind when we turn towards the possible pathologies of collective recognition. This, however, requires that we first make clear what is meant by pathologies of recognition.

\section{Defining Pathologies of Recognition}

Though widely used within critical social theory, terms like pathology and diagnosis are borrowed from the medical sciences (Honneth, 2007, 34). This can be seen as problematic in two ways. Firstly, it has turned out that defining what is pathological is difficult even in its original medical context (see e.g. Canguilhem, 1991). Nevertheless, despite the difficulties of defining what exactly constitutes a pathology, the key intuition is easily gleaned: if something is described as pathological, there is always a corresponding healthy or normal state (Canguilhem, 1991, 35, 41). In a sense, a pathology is, then, a deviation from normality or a deviation from a norm, be it a deviation from the normal functional state of a body or the normal functional state of a social system.

This leads us to the second problem. Even if we accept the key intuition that deviation from the normal is pathological, this does not yet mean that we would know the standards of normality for social systems or that we could extend any standards of normality from medical sciences to 
social philosophy. There are, of course, some senses in which the medical and the social are intertwined. Foucault (1994) hints at the possibility that social conditions have an effect on medical pathologies as well. Medical pathologies have become an issue for state-design in modern societies and thus medical issues are also social issues. However, it seems that this interaction of social and biological spheres is not what we have in mind when we talk about social pathologies. As Honneth (2014) states, social pathologies do not need to be necessarily reflected as individual pathologies or an aggregation of pathological individuals. As social pathologies do not need to have a clear individually diagnosable effect on individuals, ${ }^{5}$ the focal point is no longer an individual agent but instead "we require a conception of normality related to social life as a whole" (Honneth, 2007, 34).

In fact, social pathologies of this kind are often seen as the main focus of critical social theory. Honneth argues that Critical Theory is partly based on the intuition that successful societies maintain their standards of rationality that 'provide the members of society with the orientation according to which they can meaningfully direct their lives' (Honneth, 2009, 23-24). ${ }^{6}$ Critical Theory analyses those pathologies that are deficiencies in the social system that do not allow the members of the society to have a 'good life' (Honneth, 2009, 22) or, more precisely, do not allow for undistorted self-realization (Honneth, 2007, 37).

Defining the idea of a 'healthy' social life as something that allows agents' self-realization means that if we want to discuss pathologies of social life, we need to make 'assumptions about how the conditions of human selfrealization are in fact constituted' (Honneth, 2007, 34). It is here that we can turn back to the concept of recognition: if we see societies as systems of recognition and if we understand recognition as linked with our relationsto-self, then any society, institution, or social setting that fails to provide sufficient recognition to its members or fails to realize recognition relationships in a sufficient manner is pathological. The 'norms of recognition' that are broken in pathologies get their force from the claim that recognition is a necessary part of self-realization. This idea can also be formulated by stating that the need for recognition places normative demands on agents, and that leads into the construction of normative 'recognition institutions' which, in some sense, embody ${ }^{7}$ the said norms of recognition.

However, not every violation of the normative 'recognition order' is a social pathology, as we can have accidental misrecognition and disrespect that are not in need of social diagnosis. Similarly, we may want to limit social pathologies to those norms that are relevant for social reproduction. This is linked to the idea that in a sense the subject of the social pathologies is the social system as a whole. ${ }^{8}$ Thus, we might add systematicity and relevancy 
conditions to social pathologies - the violations of the normative order need to be systematic or recurring to be pathologies, and those violations need to be violations of the norms that are relevant for the existence of the society. As recognition is understood as a vital element of social and personal life, we can have a working definition of a pathology of recognition - systematic distortion of actions, which in 'healthy' conditions ought to follow the norms of recognition, in a way that harms the functions of a recognition system.

These pathologies can manifest in at least two ways. ${ }^{9}$ This is what is hinted at by Canivez $(2011,852)$ in saying that recognition does not only cure social pathologies but it also has pathologies of its own as a social relationship. The first way in which pathologies can manifest is that of pathologies as failures in establishing a recognition relationship or a 'recognition-deficit' (McBride, 2013, 35). These pathologies include cases where recognition is withheld or denied intentionally but also unintentional failures to recognize someone. Though it is questionable if all recognition can be distributed or shared by will (McBride, 2013, 33), the usual solution to these kinds of pathologies is granting recognition to exactly those who lack it.

The second possible way is that the pathologies of recognition are internal problems of recognition. In these cases the interpersonal relationship does exist but it is realized in some harmful manner. This may be as simple as recognizing someone in a wrong way or misinterpreting recognitive attitudes and actions. However, it is also possible that some form of recognition will become dominating at the cost of other forms (see e.g. McBride, 2013, 127-133 on the dangers of excess of esteem) or that a particular form of recognition is taken to be all that there is to recognition (Canivez, 2011, 883). Similarly, intentional or accidental use of vulnerabilities and dependencies that come with the need for recognition can be considered as distortions of authentic or properly responsive recognition (see Heikki Ikäheimo's contribution to this volume) and are thus pathological in this latter sense of pathologies of recognition.

In the end, we are left with a picture in which recognition is needed for a functioning society and a good personal life. From these needs arise the normative expectations of recognition and any systematic violations of these norms may be considered as pathologies of recognition. These pathologies come in the form of a lack or denial of recognition but also in the form of twisted social relationships that do not manage to satisfy the needs for recognition in a fulfilling manner. Now that we have a clearer picture of what pathologies of recognition are and what they mean, it is time to turn our attention to what this means in the context of collective recognition. 


\section{Pathologies of Collective Recognition}

In everyday life we are faced with a multitude of concrete issues that can be understood as problems of collective recognition. Recent contributions to the literature analyze topics ranging from international relations, war, statelessness, and immigration to the status of sexual minorities, religious groups, and ethno-national conflict as potentially pathological issues of collective recognition (see e.g. Thompson \& Yar, 2011; Martineau, Meer \& Thompson, 2012; O'Neill \& Smith, 2012). While it seems clear that recognition theory is helpful in understanding practical cases of various problems between social groups, the theoretical assumptions behind this collectivizing move remain largely underanalyzed and this is exactly the task at hand here. What is it that we mean when we talk of pathologies of collective recognition? The answer to this question can be derived from the broad definitions of collective recognition and pathologies of recognition offered above.

With the two senses of collective recognition in play, we can also see two separate ideas of collective pathology emerging: (a) systemic and (b) agential. The systemic collective pathologies (a) are related to the institutional systems of recognition that enable recognition relationships between agents. For them to be pathological, there needs to be something amiss with their constitution or realization of the recognition institution in the sense that it does not allow undistorted self-realization for those who participate in it. In other words, the recognition framework is skewed so that it does not allow its participants to fulfill their recognition needs. For example, institutional racism (e.g. separate spaces in public for black people), sexism (e.g. lower wages for women), or lack of minority rights (e.g. gay marriage rights) can be considered as pathologies of this kind. The range of pathologies shifts from the ultimate lack of recognition of one's personhood - slavery - to the severe mistaken emphasis on certain kinds of recognition - for example, the modern Western 'celebrity culture' where esteem is given for deeds and traits that are not necessarily relevant for the reproduction of the society itself (McBride, 2013, 73).

These systemic collective pathologies refer to the first sense of 'collective' recognition - collective as a collectively accepted framework of recognition - and claim that there is something wrong with the recognition institutions themselves. Obviously, claiming that these kinds of pathologies exist requires an understanding of the normality of such a system. As was hinted at in the previous section, this idea of a normality is linked, on the one hand, to individuals' possibilities for self-realization and, on the other hand, to the society as a functional whole. For Honneth $(2007,37)$, what ultimately measures the healthiness of social organizations is the way they 
allow and enable human self-realization. ${ }^{10}$ Thus the individual and their suffering or freedom are the ultimate measures even for collective pathologies. However, Honneth (2014) adds that we need to consider societies as organic wholes or organisms to really be able to talk about pathologies - and that in some senses that line of thinking has been already declared dead. The intuition is that to talk about the health of a system or a framework of recognition, that system needs to be 'alive' in some sense. Otherwise, we would be interested in its failures in a more mechanistic sense. However, the statement of the death of 'organic whole' theories of societies might be premature. For example, Guido Seddone's (2014) recent analysis understands societies as social wholes with an interest in self-preservation. Furthermore, it might be enough that we see a social system as a functionally unified entity to be able to talk about its health. ${ }^{11}$ This position includes the same background assumption that there is a right or wrong way for the functional whole to work but it lacks the biological connotations that come with the term 'organism'. It seems clear that we do not need to accept the organic line of thinking in any strong sense. If we take the thin notion of a pathology - that is, a contra-normativity - we may well see social institutions as normative, if not organic, wholes.

In the systemic sense then, a collective pathology is a dysfunction of a holistic system of recognition in a manner that can be observed from the self-realization, or lack thereof, of the agents that participate in that particular recognition framework. In the same way that it was claimed that all recognition is collective, understanding these collective pathologies can be seen as a pre-requisite for understanding any pathologies of recognition or suffering of the agents themselves within any recognition system. However, this is not completely right as in some pathologies of recognition the recognition system itself is not at fault, but instead they result from individuals themselves breaking the norms of recognition - unintentionally or of their own volition. ${ }^{12}$ This leads us to the second - agential - sense in which collectives and pathologies of recognition interlink.

What is meant by the agential sense of collective pathologies (b) is the pathologies of recognition where collectives are either subjects or objects in a pathological relationship. These can take the form of a systemic pathology where a collective agent is functioning within a pathological social framework of recognition, or a pathology of a collective agent not acting according to the norms of recognition systems.

How then do the possible pathologies where groups are subjects or objects of recognition manifest? The common factor behind the various practical cases of discrimination, ostracization, and reification is that either a group is harmed or a group causes harm in the sense of breaking the norms of recognition. In short, if we accept that there are different action positions 
for collective agents in recognition (group in relation to its individual member; group in relation to a non-member individual; group in relation to its subgroup; group in relation to an external group), this allows us to understand the distortions of recognition norms in any of these relationships as a pathology of collective recognition. Furthermore, if we understand recognition as something that takes different forms, we also need to understand pathologies as existing in these different forms. Thus, we may assume that the agential pathologies of collective recognition take the following two forms:

\begin{tabular}{|c|c|c|c|c|}
\hline $\begin{array}{l}\text { Collective } \\
\text { agent }\end{array}$ & $\leftarrow$ & $\begin{array}{c}\text { unsuccessful } \\
\text { recognition relationship }\end{array}$ & $\rightarrow$ & $\begin{array}{c}\text { External agent: } \\
\text { individual/group/... }\end{array}$ \\
\hline $\begin{array}{l}\text { Collective } \\
\text { agent }\end{array}$ & $\leftarrow$ & $\begin{array}{c}\text { unsuccessful } \\
\text { recognition relationship }\end{array}$ & $\rightarrow$ & $\begin{array}{c}\text { Internal agent: } \\
\text { individual/group/... }\end{array}$ \\
\hline
\end{tabular}

Here an unsuccessful recognition relationship can be any of the types of recognition allowed by the theory of recognition in question, and the failure of recognition may work in both directions. These relationships are also dependent on the background system of recognition norms as discussed with the systemic sense of pathologies (a).

There is no reason to think that the pathologies in relations to external agents differ logically from those between individual agents unless one can show that there are relevant differences between collective agents and individual agents in the context of recognition. ${ }^{13}$ In turn, recognition relationships with 'internal agents' have no equivalent in individual recognition relationships as it makes no sense to say that a part of an individual person is in a recognition relationship with the person of whom it is a part. Though the details of how the internal recognition functions in groups are debatable, it is often thought that this form of recognition has to exist as it is in some sense necessary for the existence of the group itself. ${ }^{14}$

The internal dynamics of groups present a potential for a specific form of pathology that does not appear in the relations to external persons. The issue stems from the fact that in collective reasoning processes, it cannot be guaranteed that individual judgments or intentions will be respected (List \& Pettit, 2004, 227). Thus, being part of a group and recognizing the group might lead into a situation where the individuals' will for self-determination is not recognized. The collective will overrides the individuals' wishes, so to speak. In fact, this is a danger in any democratic decision-making process where there is no respect for pluralism of opinions. Thus, to avoid the 
pathological forms of collective reasoning, a group needs to have suitable control mechanisms in place to ensure that individuals are not unreasonably subjected to domination by a majority. ${ }^{15}$

The internal dynamics of in-group recognition have another potentially problematic feature. Collective agents are in some sense selfsufficient and not sensitive to outside recognition. It is possible - as the possibility of secret societies shows - for a group's identity to be defined fully in its internal recognition relationships between its members. If this is the case, these groups seem to be exempt from the sensitivity of recognition by external others that is one of the key intuitions of recognition theory (McBride, 2013, 137-145). The issue of non-sensitivity to external recognition might not be severe, though, as in practice many public collective agents like corporations do care about their reputations or, to make the claim stronger, require external recognition to exist (Laitinen, 2014).${ }^{16}$ On the other hand, the stubbornness of some communities - e.g. small religious cults with 'us against the world' attitudes - might be partly explained by the selfsufficiency of the collective identity that makes external recognition largely irrelevant.

A larger set of problems that relates to both internal and external relationships has to do with identification with a group and representation of a group. Firstly, recognizing groups always runs the risk of being 'reificatory'. In other words, either someone is identified with a group they do not personally identify with or the identity that is associated with a group has not been determined by the group itself. ${ }^{17}$ It is commonplace to group people under reificatory categories (gender, race, sexuality, etc.) when in fact a great variety of identities exists within each category. The representation problems are partly similar: it is not always obvious if a group member is making judgments as a representative for the whole group or if his statements concern private issues and opinions. In short, as groups function through their individual members, we need to be careful to make sure whom the person is representing - himself or the group as a whole. Otherwise, we face the danger of forming mistaken attitudes towards the individual and the group.

Finally, collective power is an issue that has a potentially large role in the formation of pathologies. Large collective agents often have more resources (wealth, physical power) than individuals or small groups and this creates a potentially unequal setting for the struggles for recognition. Some claims for recognition can be easily dismissed when there is no crowd strength behind them. The voice of many is more easily heard than a voice of one. Though the imbalance of power does not necessarily lead to pathological recognition relationships, it is easy to see that it raises the potential for them. 
This list of possible pathologies of collective recognition is not meant to be exhaustive. It only highlights the potential areas where problems might arise when the idea of collective agents is included in the dynamics of recognition relationships. However, the usefulness and the applicability of the above ideas to collective pathologies of recognition is largely dependent on the background theories of agency, personhood, and recognition.

\section{In Conclusion: a Choice of Ontological Commitments}

The main aim of this article was to describe what we might mean by pathologies of collective recognition. It is clear that there is no simple and straightforward definition of a collective pathology. Even in the broad sense of the term it may refer either to systemic problems of the recognition framework and social reproduction or to pathologies that concern collective agents. Furthermore, there are issues related to the functioning of collectives - collective power, collective reasoning issues, collective identification and representation, self-sufficiency - that present a potential situation in which pathologies of recognition can occur. Both senses of collective pathologies are present in the current recognition theoretical discussions - though they are not clearly distinguished. It is suggested here that this distinction is theoretically useful as it helps us to evaluate the (social) ontological commitments that one is required to make if one aims to discuss certain types of pathologies of recognition.

Though it is commonly accepted that recognition relations derive their practical forms within a larger normative framework, the ontological status of collective agents is more contested. In fact, the differentiation between collective acts of recognition as opposed to individual acts of recognition is unclear and the recognition-theoretical paradigm does not share a unified stance on the status of collectives. Instead, theories oscillate between Durkheimian collectivism that accepts groups as agents (e.g. Taylor) and Weberian individualism that wants to conceive all recognition ultimately as relationships between singular individuals (e.g. Honneth). Thus it is unclear what, if any, conceptual tools are available for recognition theorists to use to analyze the concrete issues of collective recognition and its pathologies.

Acceptance of group agency does not necessarily mean that one embraces some strange ontology. After all, it is equally questionable if one can draw any ontological borders on the individual level. Perhaps it is good to ask then what purpose the theory itself serves and what it aims to understand and analyze. If a recognition theory aims to understand society and collective movements, and if, in doing so, it uses the concept of a collective pathology, what ontological commitments does a theorist need to make? At least, collectives (groups, societies, and so forth) need to be seen 
as functional wholes that are either healthy or not. This is a thought that is already present in the Hegelian tradition - a society as an organism. However, we may want to steer away from conflating collective agents and normative systems, as only agents seem to suffer from pathologies while normative systems might be detrimental for the agents that function within it. Thus, any theorist needs to make clear what exactly is at stake when something is pathological - is it the sufferance of the agents within a system or the impossibility of the functioning and re-production of the system itself? For the latter to be counted as pathological, we may need to posit - like Seddone (2014) does - an interest in self-preservation for the collective. Furthermore, there is no guarantee that if we do posit this kind of selfinterest for a collective, that this interest is in harmony with individuals' interests in self-preservation and freedom. In the end, this means that any theorist of collective pathologies needs first to make the ontological status of collectives clear and, secondly, to make it clear exactly how the collective pathologies are related to individual interests and individual suffering.

Onni Hirvonen (onni.hirvonen@jyu.fi) has a $\mathrm{PhD}$ in philosophy from Macquarie University, Sydney, and he is currently doing post-doctoral research at University of Jyväskylä. His work focuses on the interplay of identities and institutions from a recognition-theoretical perspective.

\section{Bibliography}

Anderson, J. (2013) 'The Fragile Accomplishment of Social Freedom' Krisis: Journal for Contemporary Philosophy issue 1, 18-22

Benhabib, S. (2002) The Claims of Culture: Equality and Diversity in the Global Era Princeton: Princeton University Press

Canguihem, G. (1991) The Normal and the Pathological New York: Zone Books

Canivez, P. (2011) 'Pathologies of Recognition' Philosophy and Social Criticism 37(8), 851-887

Foucault, M. (1994) 'The Birth of Social Medicine' in J. D. Faubion (Ed.), R. Hurley (trans.) et. al. Essential Works of Foucault: 1954-1984, Vol. 3: Power New York: The New Press, pp. 134-156

Fraser, N. (2000) ‘Rethinking Recognition' New Left Review vol. 3, 107-120 
French, P. A. (1979) 'The Corporation as a Moral Person' American Philosophical Quarterly 16(3), 207-215

Hirvonen, O. (2013) Concepts of Group Recognition PhD Dissertation, Macquarie University

Honneth, A. (1995) The Struggle for Recognition: The Moral Grammar of Social Conflicts (trans. J. Anderson) Cambridge: The MIT Press

Honneth, A. (2007) Disrespect: The Normative Foundations of Critical Theory Cambridge: Polity Press

Honneth, A. (2009) Pathologies of Reason. On the legacy of critical theory New York: Columbia University Press

Honneth, A. (2011) 'Rejoinder' in D. Petherbridge (ed.) Axel Honneth: Critical Essays: With a Reply by Axel Honneth Leiden/Boston: Brill, pp. 391-421

Honneth, A. (2014) 'Diseases of Society: Approaching a Nearly Impossible Concept' Social Research: An International Quarterly 81(3), 679-699

Ikäheimo, H. (2002) 'On the Genus and Species of Recognition' Inquiry: An Interdisciplinary Journal of Philosophy 45(4), 447-462

Ikäheimo, H. (2007) 'Recognizing Persons' Journal of Consciousness Studies 14(5-6), 224-247

Ikäheimo, H. (2014) Anerkennung Berlin: De Gruyter

Kusch, M. (2014) 'The Metaphysics and Politics of Corporate Personhood' Erkenntnis 79(9), 1587-1600

Laitinen, A. (2007) 'Sorting Out Aspects of Personhood: Capacities, Normativity and Recognition' Journal of Consciousness Studies 14(5-6), 24870

Laitinen, A. (2014) 'Collective Intentionality and Recognition from Others' in A. Konzelman-Ziv \& H. B. Schmid (eds.) Institutions, Emotions, and Group Agents. Contributions to Social Ontology Heidelberg: Springer, pp. 213-227

Lindemann, T. (2010) Causes of War. The Struggle for Recognition Colchester: ECPR Press 
Lindemann, T. \& Ringmar, E. (eds.) (2012) The International Politics of Recognition Boulder: Paradigm Publishers

List, C. \& Pettit, P. (2004) 'Aggregating Sets of Judgments: Two Impossibility Results Compared' Synthese 140(1), 207-235

List, C. \& Pettit, P. (2011) Group Agency. The Possibility, Design and Status of Corporate Agents Oxford: Oxford University Press

Martineau, W., Meer, N. \& Thompson, S. (2012) 'The Politics of Misrecognition' Res Publica 18(1), 1-106

McBride, C. (2013) Recognition Cambridge: Polity Press

O'Neill, S. \& Smith, N. (eds.) (2012) Recognition Theory as Social Research: Investigating the Dynamics of Social Conflict New York: Palgrave Macmillan

Pettit, P. \& Schweikard, D. (2006) 'Joint Actions and Group Agents' Philosophy of the Social Sciences 36(1), 18-39

Seddone, G. (2014) Collective Intentionality, Norms and Institutions: A Philosophical Investigation about Human Cooperation Frankfurt: Peter Lang

Siep, L. (1974) 'Der Kampf um Anerkennung: Zu Hegels Auseinandersetzung mit Hobbes in den Jenaer Schriften' Hegel-Studien, vol. 9, 155-207

Taylor, C. (1994) 'The Politics of Recognition' in A. Gutmann (ed.) Multiculturalism: Examining the Politics of Recognition Princeton: Princeton University Press, pp. 25-74

Thompson, S. (2006) The Political Theory of Recognition. A Critical Introduction Cambridge: Polity Press

Thompson, S. \& Yar, M. (eds.) (2011) The Politics of Misrecognition Surrey: Ashgate Publishing

Tuomela, R. (2013) Social Ontology. Collective Intentionality and Group Agents Oxford: Oxford University Press 
Yar, M. (2011) "“And Every Cruelty Will Cloud It": On Love, Damaged Selfhood and Criminal Harm' in S. Thompson \& M. Yar (eds.) The Politics of Misrecognition Surrey: Ashgate Publishing, pp. 125-144

Young, I. M. (2000) Inclusion and Democracy Oxford: Oxford University Press

\section{Endnotes}

1 I would like to thank, firstly, Alison Beale for her great work in proofreading this article and, secondly, the anonymous referee and the members of the Pathologies of Recognition research group for their helpful comments and feedback. I am also grateful for The Ella and Georg Ehrnrooth Foundation for funding this research.

${ }^{2}$ As stated in the introduction to this collection, the term recognition can also be understood in various other senses that differ from the Hegelian recognition of persons.

${ }^{3}$ Here 'collective' is used in a very loose sense as an umbrella term for all things that are related to groups of people. This is separate from the more detailed social-ontological use of 'collective' by, for example, Pettit and Schweikard (2006) who define collectives as something opposed to individuals and overriding individual reasoning.

${ }^{4}$ For a counter-argument, see Kusch (2014). He claims that the unity of the historical tradition of personification is overstated in List and Pettit's work.

5 Though it is assumed that some individual manifestations of social pathologies need to be seen, since societies are not ontologically independent from individuals. It would be difficult to imagine a pathological society where no individual's well-being - in the broadest sense of the term - has suffered.

${ }^{6}$ The second - methodological - intuition behind Critical Theory is that the standards of rationality and their pathologies can be explained with the help of empirical social sciences (Honneth, 2009, 29).

${ }^{7}$ As becomes clear with the idea of 'normative surplus' (Honneth, 2011, 410411), the institutions rarely embody the norms completely or realize the full potential of the abstract ideas they are based on.

${ }^{8}$ Though the maintenance of the normative recognition systems is relevant 
for social reproduction, not every social pathology need be a pathology of recognition. As Honneth (2014) points out, if a society is to preserve itself, it needs to care about 'external nature, social shaping of inner nature and regulation of inter-human relations'. While the two last issues, socialization and social relations, can be considered as dealing with recognition between persons, society's relation to and work on external nature is not fundamentally a matter of recognition.

${ }^{9}$ These two ways correspond closely to what might be called a distinction between misrecognition and non-recognition. In non-recognition the other is not recognized at all while misrecognition indicates distorted or incomplete forms of recognition (Yar, 2011, 129).

${ }^{10}$ Honneth $(2007,37)$ notes that this does not mean that it is easy to agree on the standards of evaluation for the social pathologies because we may well have disagreements on the foundational concept of self-realization.

${ }^{11}$ This line of thought is especially entertained in the functionalist theories of agency. As List and Pettit (2011) argue, the constituting matter of collective or any other agents does not matter as much as the way in which the agent performs in its environment.

${ }^{12}$ In the cases where the system of recognition cannot be faulted, this 'going against the norms' can be seen as immoral. On the other hand, if the system of recognition itself is at fault, it can be considered unethical.

${ }^{13}$ To speak of groups as agents in Hegelian recognition, one needs to make a broad assumption that collective agents have some recognition needs of their own. I have argued elsewhere (Hirvonen, 2013) that group agents are not capable of participating in all forms of Honnethian recognition. Collective agents are not usually considered to have emotional needs in the sense that they would require love. However, more rational respect and esteem are forms of recognition that groups are capable of reciprocating.

14 This is often called the 'common acceptance' model of institutions. As formulated by Searle $(1995,39-40)$ any institutions, groups, or social facts need to be recognized to exist.

15 Canivez (2011, 883) discusses a similar issue in saying that mere participation in the state's actions does not count as proper recognition. Instead, the state recognizes its members by securing their rights. 
${ }^{16}$ Laitinen's (2014) claim is that the self-sufficient groups are a special case while most groups are dependent on external recognition.

17 The themes of reification and false essentialization in the context of recognition have been extensively discussed in feminist literature. See, for example, Benhabib (2002), Fraser (2000), or Young (2000). 